\title{
Effect of oxygen addition on the formation of
}

\section{isothermal $\omega$ phase in Ti-Fe alloys}

\author{
Sengo Kobayashi, Shota Sasaki ${ }^{* 1}$, Sota Kawano ${ }^{* 2}$, Renta Sasaki ${ }^{* 3}$, Satoshi Okano
}

Department of Materials Science and Biotechnology, Graduate School of Science and Engineering, Ehime University, Matsuyama 790-

*1 Undergraduate student (now MIURA Co., Ltd.), *2 Graduate Student (now JTEKT Co.),

*3 Graduate student, Ehime University

Corresponding author: Sengo Kobayashi, kobayashi.sengo.me@ehime-u.ac.jp

The effect of the addition of oxygen on the formation of microstructure cooled from the $\beta$ phase of Ti-Fe alloy was examined. The alloy ingots of Ti-(4, 5, 6, 7, 8, 9 and 10) at.\% Fe and Ti-8 at.\% Fe-(1 and 3) at.\% $\mathrm{O}$ were arc-melted. They were homogenized at $1200{ }^{\circ} \mathrm{C}$ for $3.6 \mathrm{ks}$ and then hot-rolled at $850{ }^{\circ} \mathrm{C}$ into 1.5 -mm thick sheets. The disk specimen was fabricated and then put in the differential thermal analysis (DTA) apparatus. The disk in the DTA was heated at $1000{ }^{\circ} \mathrm{C}$ for $0.6 \mathrm{ks}$ in the $\beta$ phase and then cooled to room temperature at a rate of $50{ }^{\circ} \mathrm{C} / \mathrm{min}$. The microstructure was examined by an optical microscope after the DTA experiment. In the Ti-(7 and 8) Fe alloys the $\omega$ phase formed during cooling. The addition of oxygen in the Ti- $8 \mathrm{Fe}$ alloy promoted the $\beta \rightarrow \alpha$ transformation. Furthermore, the addition of one at. $\%$ oxygen in the Ti- $8 \mathrm{Fe}$ alloy promoted $\beta \rightarrow \omega_{\mathrm{i}}$ transformation, while the addition of three at. $\%$ oxygen suppressed the $\beta \rightarrow \omega_{i}$ transformation during cooling.

\section{$\underline{\text { 1. Introduction }}$}

Titanium alloys are used for aircraft, automobile, and medical materials because of their high specific strength, high heat resistance, and excellent corrosion resistance ${ }^{[1-5]}$. When using a titanium alloy as a structural material, microstructure control is performed to adjust mechanical properties such as strength and ductility. The microstructure is often controlled by phase transformation, which will be changed by alloying elements. Ubiquitous elements of iron and oxygen have been treated as impurity elements of titanium alloy owing to a cause of brittleness, but adding them to titanium has the advantage of improving strength. The addition of iron in a titanium alloy works as a $\beta$ phase stabilizer. The microstructure formed by quenching from the $\beta$ phase in a titanium alloy varies by increasing the amount of iron as follows: $\alpha^{\prime}$ martensite, $\beta+\omega_{\mathrm{a}}$ (athermal $\omega$ ), and $\beta$ (no phase transformation). The iron addition in titanium also 
promotes the formation of $\omega_{\mathrm{i}}$ (isothermal $\omega$ ) phase. The addition of oxygen in a titanium alloy, on the other hand, works as an $\alpha$ phase stabilizer. The oxygen addition promotes precipitation of $\alpha$ phase in the $\beta$ phase. The $\beta \rightarrow \alpha$ " martensitic transformation would be suppressed by the addition of oxygen ${ }^{[6-10]}$. The $\beta \rightarrow \omega_{\mathrm{a}}$ and $\beta \rightarrow \omega_{\mathrm{i}}$ transformation would also be suppressed by the addition of oxygen ${ }^{[11,12]}$. The authors' group also showed the $\beta \rightarrow \omega_{\mathrm{a}}$ transformation in Ti-Nb alloy was suppressed by the oxygen addition ${ }^{[13]}$. However, Niinomi et al. revealed the oxygen addition stabilized the $\omega_{i}$ phase in the Ti-29Nb-13Ta-4.6Zr alloy ${ }^{[14]}$. The effects of oxygen addition on the transformation of the $\beta \rightarrow \omega_{i}$ phase are still under discussion. In this study, therefore, the effect of the oxygen addition on the formation of the $\omega_{i}$ phase during cooling from the $\beta$ phase in Ti-Fe alloy.

\section{Experimental procedures}

Sponge titanium ( $>99$ mass\%), granular niobium (> 99.9 mass\%), TiO powder (99.9 mass\%), and titanium foil ( $>99.5$ mass $\%)$ were used for the sample preparation. These pure metals and oxides were weighed for a nominal alloy composition of Ti- $(4,5,6,7,8,9$ and 10) at.\% Fe and Ti-8 at.\% Fe-(1 and 3) at.\% O. The TiO powder was wrapped in titanium foil during weighing. A button-shaped ingot of $10 \mathrm{~g}$ was arc-melted using a tungsten electrode in a water-cooled copper hearth. A pure titanium block was melted to purify the argon gas atmosphere before argon arc melting. The alloy button was melted eight times and was flipped over before each melting run to create a uniform composition. The oxygen-free alloys contained approximately 0.25 at.\% ( 0.075 mass\%) oxygen; however, in this study, they are displayed as Ti-(4, 5, 6, 7, 8, 9 and 10) Fe or Ti-8-at.\% Fe-0 at.\% O because oxygen was not intentionally added. Hereafter, the composition will be displayed in the atomic percent, and the unit will be omitted. The ingot was wrapped with tantalum foil, and after evacuating, it was sealed in a quartz tube filled with argon at $0.02 \mathrm{MPa}$. It was homogenized at $1200{ }^{\circ} \mathrm{C}$ for $3.6 \mathrm{ks}$ in the $\beta$ phase and then quenched into iced brine. The homogenized alloy button was hot-rolled at $850{ }^{\circ} \mathrm{C}$ to obtain an approximately 1.5 -mm thick plate sample. The plate sample was cut into disks of $4 \mathrm{~mm}$ in diameter, and the samples were subjected to a solid solution treatment at temperatures of $1000^{\circ} \mathrm{C}$ for $0.6 \mathrm{ks}$ under argon gas flow in the differential thermal analysis (DTA) apparatus. The DTA measurement was carried out during cooling from $1000{ }^{\circ} \mathrm{C}$ at a cooling rate of $50^{\circ} \mathrm{C} / \mathrm{min}$. For the microstructure analysis after DTA measurement, the sample was etched with an $8 \% \mathrm{HF}$ and $20 \% \mathrm{HNO}_{3}$ aqueous solution and observed using an optical microscope.

\section{$\underline{\text { 3. Results and Discussion }}$}

\subsection{Influence of the iron addition on the phase transformation during cooling from $1000^{\circ} \mathrm{C}$}

Figure 1(a) shows the DTA curves of the Ti-(4, 5 and 6) Fe alloys cooled from $1000{ }^{\circ} \mathrm{C}$ in the $\beta$ phase. The exothermic peak of precipitation of $\alpha$ phase was detected in the Ti-(4, 5 and 6) $\mathrm{Fe}$ alloys at around 670,585 and $570^{\circ} \mathrm{C}$, indicating iron addition suppressed the $\alpha$ phase precipitation. Formation of the $\alpha$ phase in the intragranular grain of the $\beta$ phase was observed in the Ti- $(4,5$ and 6$)$ Fe alloys, as shown in Fig. 2(a). The exothermic peak of $\alpha$ precipitation was not detected in the Ti-(7, 8, 9 and 10) Fe alloys, as shown in Fig. 1(b), although the small amount of $\alpha$ precipitation was observed at grain boundaries of Ti-(7 and 8) Fe alloys as shown in Fig. 2(b). In Fig. 1(b), another exothermic peak of the $\omega_{\mathrm{i}}$ phase was appeared at around 380 and $350{ }^{\circ} \mathrm{C}$ for Ti-(7 and 8) Fe alloys. There is no clear 
exothermic peak in the DTA curves of Ti-(9 and 10) Fe alloys, indicating the suppression of formation of both $\alpha$ and $\omega_{i}$ phases in these alloys.

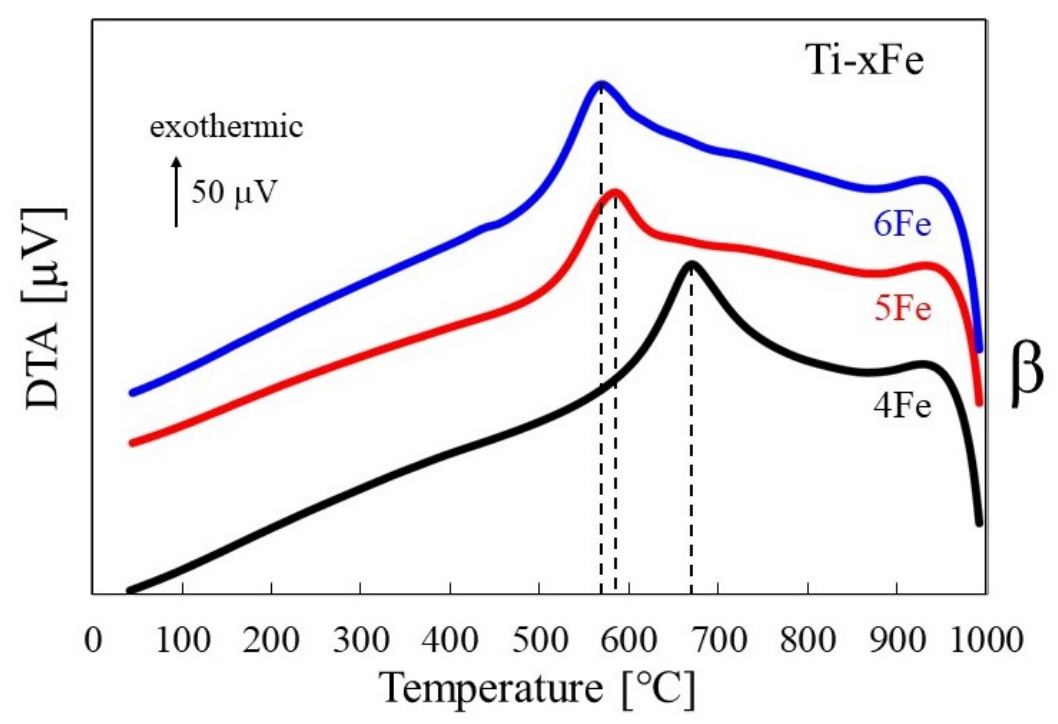

Fig. 1 (a) Differential thermal analysis of Ti-(4, 5 and 6)Fe alloys during cooling from $1000{ }^{\circ} \mathrm{C}$ at a cooling rate of $50{ }^{\circ} \mathrm{C} / \mathrm{min}$. Dotted lines indicate the temperature of the exothermic peaks for the DTA curves. 


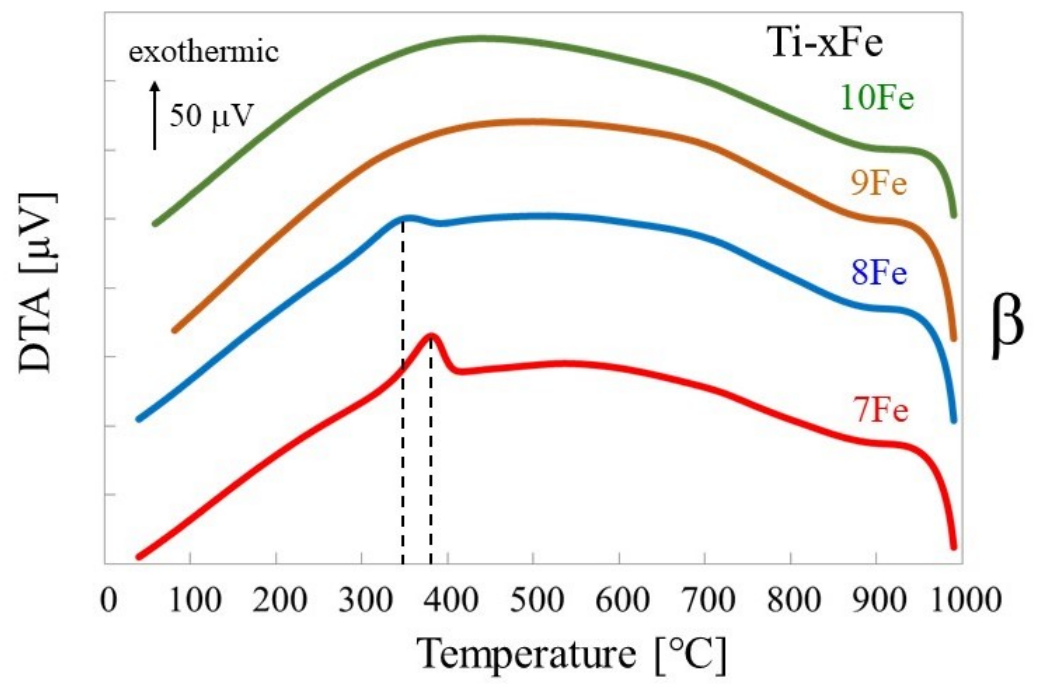

Fig. 1 (b) Differential thermal analysis of Ti-(7, 8, 9 and 10)Fe alloys during cooling from $1000{ }^{\circ} \mathrm{C}$ at a cooling rate of $50{ }^{\circ} \mathrm{C} / \mathrm{min}$. Dotted lines indicate the temperature of the exothermic peaks for the DTA curves.
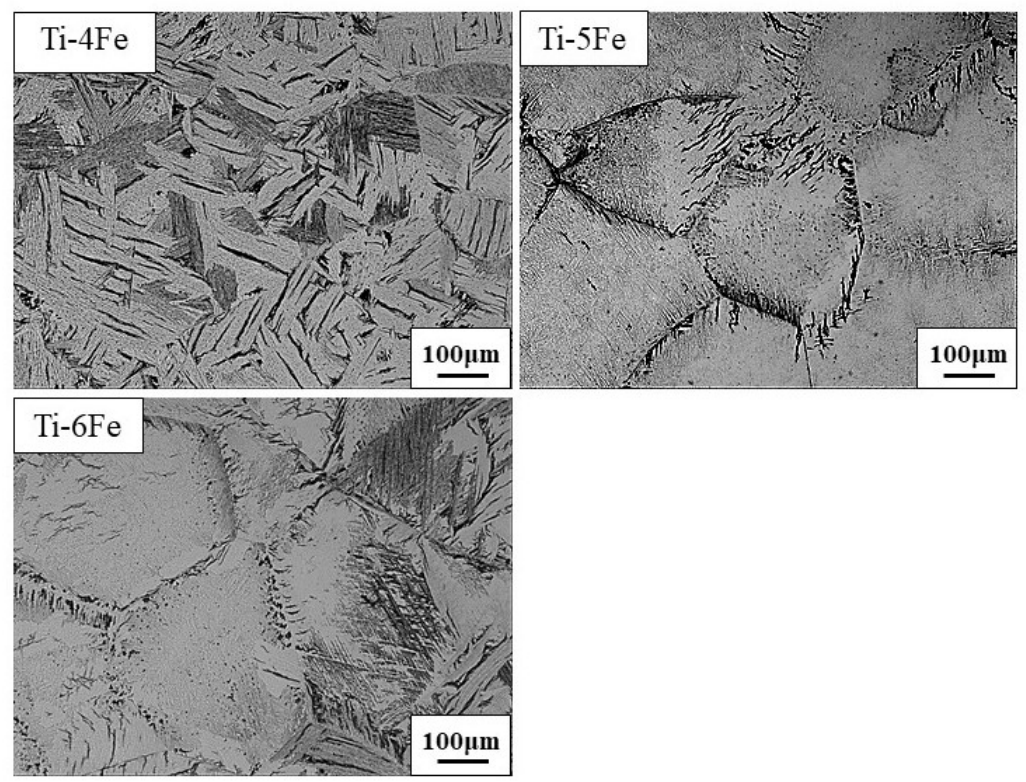
Fig. 2 (a) Optical micrographs for the Ti-(4, 5 and 6)Fe alloys after DTA experiments.
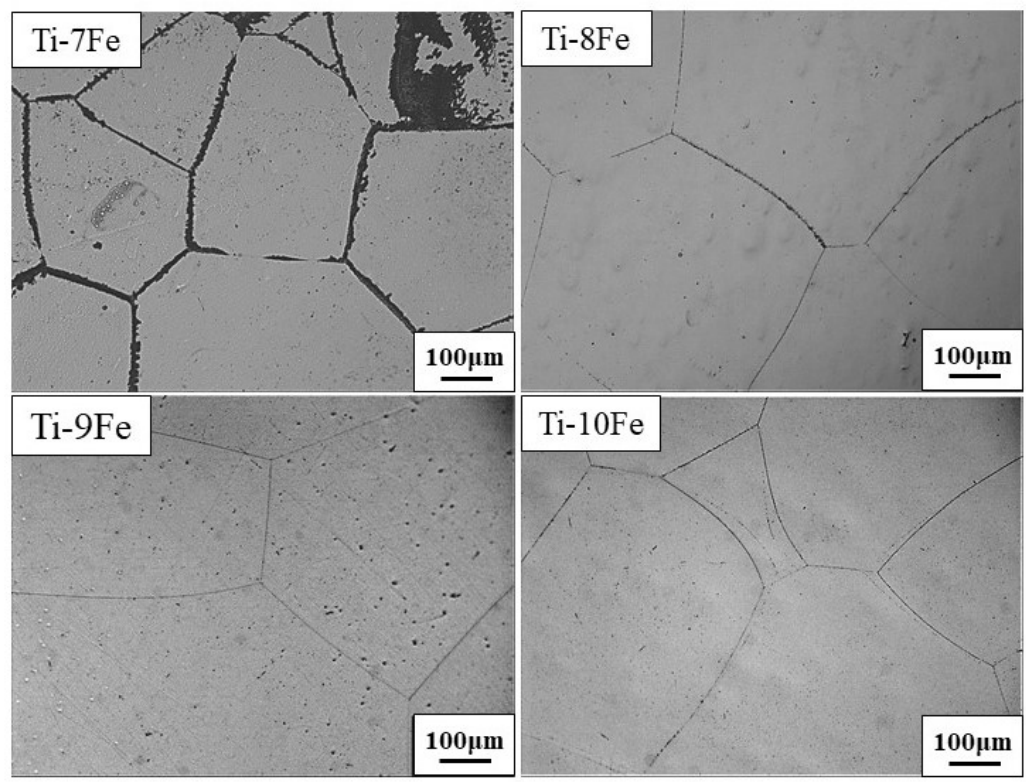

Fig. 2 (b) Optical micrographs for the Ti-(7, 8, 9 and 10)Fe alloys after DTA experiments.

\subsection{Influence of the oxygen addition on the phase transformation in the Ti-8Fe alloy during cooling from $1000^{\circ} \mathrm{C}$}

Figure 3 shows the DTA curves of the Ti-8Fe-(0, 1 and 3) $\mathrm{O}$ alloys cooled from $1000{ }^{\circ} \mathrm{C}$ in the $\beta$ phase. As mentioned in Fig. 1(b), the exothermic peak of the $\omega_{\mathrm{i}}$ phase formation was observed at around $350{ }^{\circ} \mathrm{C}$ in the Ti-8Fe alloy, while two exothermic peaks of the $\alpha$ and $\omega_{i}$ phases were detected at around 560 and $370{ }^{\circ} \mathrm{C}$ in the Ti-8Fe-1O alloy, respectively. The addition of one at $\%$ oxygen promoted the $\alpha$ phase formation. The exothermic peak of the transformation of $\omega_{i}$ phase appeared at a temperature of $20{ }^{\circ} \mathrm{C}$ higher than that in the Ti-8Fe alloy, indicating the oxygen addition also promoted the $\omega_{i}$ phase formation. The formation of $\alpha$ phase at around $560{ }^{\circ} \mathrm{C}$ should release iron atoms from $\alpha$ phase into the $\beta$ phase matrix. As shown in Fig 1(b), the increase of iron content from 8 to 9 at $\%$ suppressed $\omega_{i}$ phase formation. However, the temperature of the exothermic peak of $\omega_{i}$ phase in Ti-8Fe-1O alloy appeared at a higher temperature than that in Ti-8Fe alloy, implying that the oxygen played as an $\omega_{i}$ phase former in titanium alloy. The one exothermic peak of $\alpha$ phase was observed in the DTA curve of the Ti-8Fe-3O alloy at around $700{ }^{\circ} \mathrm{C}$. Acceleration of formation of the $\alpha$ phase was observed by the addition of three at $\%$ oxygen, while suppression of formation of the $\omega_{i}$ phase occurred. Microstructures of the Ti- $8 \mathrm{Fe}-(0,1$ and 3$) \mathrm{O}$ alloys after the DTA experiments are shown in Fig. 4. The $\alpha$ phase particles formed not only at the grain boundaries but also in the intragranular $\beta$ phase in the Ti-8Fe-(1 and 3)O alloys. The amount of the $\alpha$ phase particles increased with increasing oxygen concentration. The morphology of the $\alpha$ phase changed from the laths in the Ti-Fe alloys to the particles in Ti-Fe-O alloys. The $\alpha$ phase 
particles formed homogeneously in the intragranular $\beta$ phase in the Ti-8Fe with oxygen addition. The phase diagram of Ti-O system shows the addition of oxygen in titanium stabilizes the $\alpha$ phase. The same effect of the addition of oxygen on the $\alpha$ phase formation was also observed in the Ti-Fe alloys.

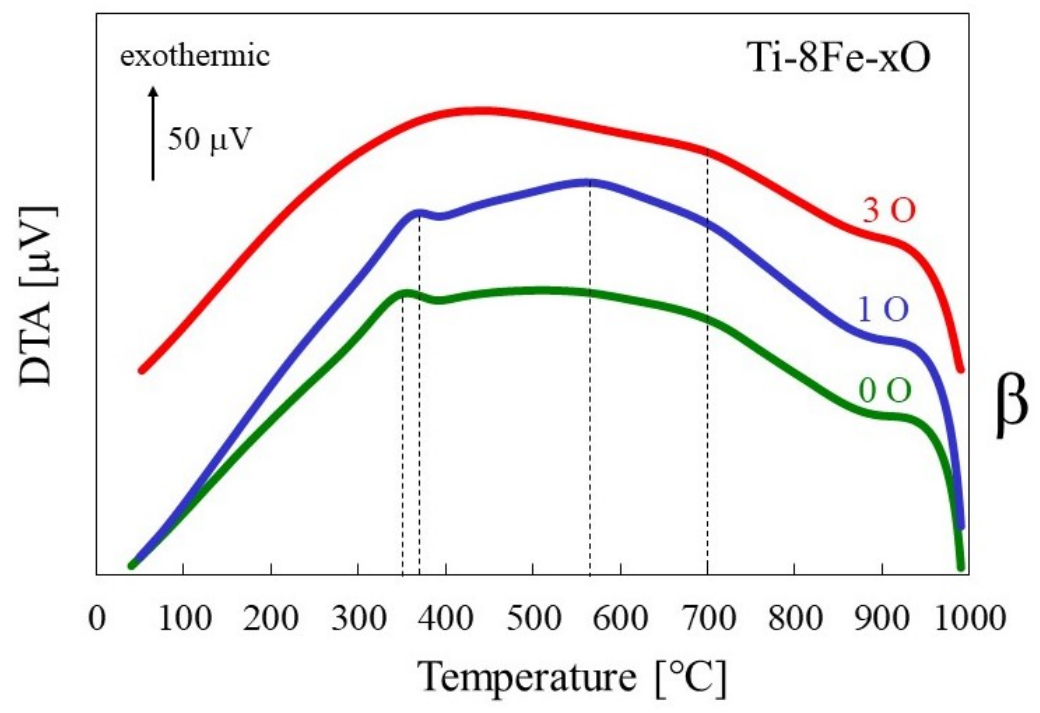

Fig. 3 Differential thermal analysis of Ti-8Fe-(0, 1 and 3)O alloys during cooling from $1000{ }^{\circ} \mathrm{C}$ at a cooling rate of $50{ }^{\circ} \mathrm{C} / \mathrm{min}^{\circ} \mathrm{Dotted}$ lines indicate the temperature of the exothermic peaks for the DTA curves. 

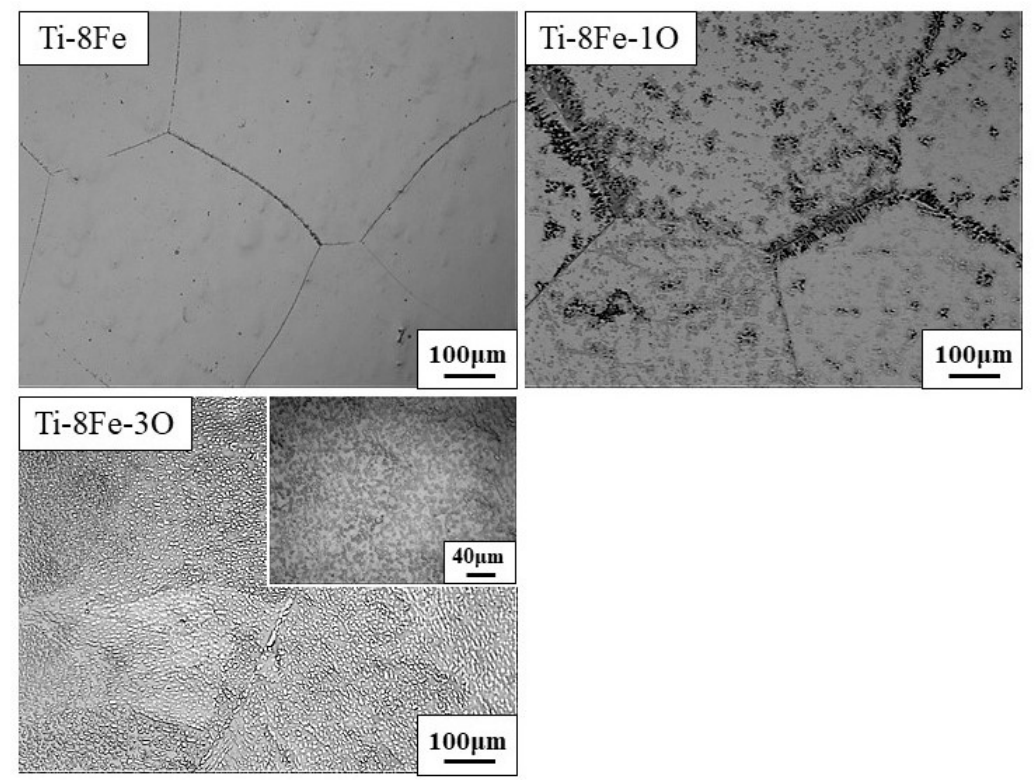

Fig. 4 Optical micrographs for the Ti-8Fe-(0, 1 and 3)O alloys after DTA experiments.

The addition of one at $\%$ oxygen accelerated the $\omega_{i}$ phase formation, while the addition of three at $\%$ oxygen suppressed $\omega_{i}$ phase formation, as shown in Fig. 3. The acceleration of the $\beta \rightarrow \omega_{i}$ transformation by the oxygen addition could be because of the increase of the chemical driving force of the $\beta \rightarrow \omega_{i}$ transformation or the decrease of the strain energy for the formation of $\omega_{i}$ phase in the $\beta$ phase. To quantitatively evaluate the chemical driving force of the $\beta \rightarrow \omega_{i}$ transformation, it is necessary to clarify the $\mathrm{Fe}$ and $\mathrm{O}$ concentration dependence of the $\omega_{i}$ phase free energy of the Ti-Fe-O alloy. Their information on the $\omega_{i}$ phase is unknown. However, Niinomi et al. recently investigated the effect of oxygen addition on the microstructural changes of Ti-29Nb-13Ta-4.6Zr (mass\%) alloy and revealed that the $\omega_{i}$ phase was stabilized by the oxygen addition ${ }^{[14]}$. They also showed that the $\omega_{i}$ phase contained a higher amount of oxygen than that in the matrix, indicating that oxygen stabilized the $\omega_{i}$ phase ${ }^{[15]}$. The free energy of $\omega_{i}$ phase would be decreased by containing oxygen in the $\omega_{i}$ phase, which leads to an increase in the driving force of $\beta \rightarrow \omega_{i}$ transformation. Thus, the acceleration of $\omega_{i}$ phase formation in the Ti-8Fe-1O was owing to the increase of the driving force of $\beta \rightarrow \omega_{i}$ transformation by the addition of oxygen. On the other hand, in the Ti-8Fe-3O alloy, the $\beta \rightarrow \omega_{\mathrm{i}}$ transformation was suppressed, or the transformation-start temperature was lowered, and the $\beta \rightarrow \omega_{i}$ transformation was suppressed. If the driving force of the $\beta \rightarrow \omega_{i}$ transformation is increased by the addition of oxygen, the $\beta \rightarrow \omega_{i}$ transformation should be promoted with the oxygen concentration increases. Therefore, the factor by which the $\beta \rightarrow \omega_{i}$ transformation is suppressed is not due to the influence of oxygen addition on the chemical free energy. On the other hand, concerning the change in strain energy when the $\omega_{i}$ phase is formed in the $\beta$ phase, oxygen occupies at an interstitial position, and the lattice is locally distorted and increases strain energy. The crystal structure change from $\beta$ phase to $\omega_{i}$ phase is caused by partial collapse of the $\{111\}$ plane of $\beta$ phase in the $<111>$ direction, and such displacement of the atomic plane is inhibited by strain fields. Therefore, the 
strain field owing to oxygen atoms is one important factor of suppression of $\beta \rightarrow \omega_{i}$ transformation. In the Ti- $8 \mathrm{Fe}-1 \mathrm{O}$ alloy, since the additional strain energy generated during the $\beta \rightarrow \omega_{i}$ transformation by one at $\%$ oxygen is smaller than the decrease of the chemical free energy by the oxygen concentrated $\omega_{\mathrm{i}}$ phase formation so that $\beta \rightarrow \omega_{\mathrm{i}}$ transformation is promoted. On the other hand, in the Ti- $8 \mathrm{Fe}-3 \mathrm{O}$ alloy, the contribution of the strain energy increase is larger than the decrease in chemical free energy of the oxygen concentrated $\omega_{i}$ phase formation, leading to the suppression of the $\beta \rightarrow \omega_{\mathrm{i}}$ transformation. When the $\alpha$ phase was formed in Ti-8Fe-1O or Ti-8Fe-3O alloys during cooling from $1000{ }^{\circ} \mathrm{C}$, iron atoms were released from $\alpha$ phase into the $\beta$ phase and iron concentration in the $\beta$ phase increased. According to Fig. 1(b), the $\beta$ phase was more stabilized by the increase of iron in the Ti-8Fe alloy, and the $\beta \rightarrow \omega_{i}$ transformation could be suppressed. The enrichment of iron in the $\beta$ phase owing to precipitation of the $\alpha$ phase is another factor to suppress the formation of $\omega_{i}$ phase in the Ti-8Fe-3O alloy.

\section{$\underline{\text { 5. Conclusions }}$}

The influence of oxygen addition on the formation of the microstructure in Ti-Fe alloys cooled from the $\beta$ phase was examined, and the following conclusions were obtained.

(1) The $\beta \rightarrow \alpha$ transformation in the Ti-8Fe alloy was promoted by the addition of oxygen. The amount of the $\alpha$ phase was increased with increasing oxygen concentration. The oxygen addition promoted homogeneous precipitation of the $\alpha$ particles. The addition of oxygen increased the driving force of $\beta \rightarrow \alpha$ transformation and increased the number of nucleation of the $\alpha$ particles.

(2) The effect of the oxygen addition on the $\beta \rightarrow \omega_{i}$ transformation in the Ti-Fe alloys was changed depending on the amount of oxygen. The promotion of $\beta \rightarrow \omega_{i}$ transformation occurred up to one at $\%$ oxygen addition, while suppression of it was induced by the addition of three at $\%$ oxygen. The oxygen addition could stabilize the $\omega_{i}$ phase and increase the driving force of $\beta \rightarrow \omega_{i}$ transformation, and, it would also increase strain energy for $\beta \rightarrow \omega_{i}$ transformation. The oxygen addition up to one at $\%$, the driving force for $\beta \rightarrow \omega_{i}$ transformation was greater than the strain energy so that oxygen addition promoted $\omega_{\mathrm{i}}$ transformation. The amount of $\omega_{\mathrm{i}}$ phase decreased in the Ti-8Fe-3O alloy. The inhibition of the atomic plane displacement required for the $\beta \rightarrow \omega_{i}$ transformation was induced by the strain field of three at $\%$ oxygen. Furthermore, oxygen addition promoted the formation of $\alpha$ phase, which released iron atoms from $\alpha$ phase into $\beta$ phase. The increase in iron concentration in $\beta$ phase in Ti-8Fe-3O alloy also suppressed the formation of $\omega_{i}$ phase.

\section{$\underline{\text { Acknowledgments }}$}


This work was supported in part by the education and research funds of the Light Metal Educational Foundation, Inc. This work was also supported in part by JKA and its promotion funds (27-165) from Auto Race.

\section{References}

1 I. Inagaki, T. Takechi, Y. Shirai, and N. Ariyasu: Nippon Steel Sumitomo Met. Tech. Rep., 2014, vol. 106, pp. $22-27$.

2

3
F.H. Froes, H. Friedrich, and D. Bergoint: JOM, 2004, vol. 2, pp. 40-44.

D. Banerjee and J.C. Williams: Acta Mater., 2013, vol. 61, pp. 844-879.

L.Le Guéhennec, A. Soueidan, P. Layrolle, and Y. Amouriq: Dent. Mater., 2007, vol. 23, pp. 844-854.

S. Nishikori: J. Japan Inst. Light Met, 2005, vol. 55, pp. 557-560.

H. Kim, H. Hosoda, and S. Miyazaki: J. Japan Inst. Light Met, 2005, vol. 55, pp. 613-617.

J. Il Kim, H. Kim, H. Hosoda, and S. Miyazaki: Mater. Trans., 2005, vol. 46, pp. 852-857.

M. Tahara, T. Inamura, H. Kim, H. Hosoda, and S. Miyazaki: J. Japan Inst. Light Met, 2012, vol. 62, pp. $257-262$.

M. Tahara, H. Kim, T. Inamura, H. Hosoda, and S. Miyazaki: Acta Mater., 2011, vol. 59, pp. 6208-6218.

H. Kim: Mater. Japan, 2014, vol. 53, pp. 11-17.

J.C. Williams, B.S. Hickman, and D.H. Leslie: Metall. Trans., 1971, vol. 2, pp. 477-484.

M. Ikeda, S. Komatsu, T. Sugimoto, and K. Kamei: J. Japan Inst. Met., 1991, vol. 55, pp. 260-266.

S. Kawano, S. Kobayashi, and S. Okano: Mater. Trans., 2019, vol. 60, in press.

M. Niinomi and M. Nakai: Mater. Sci. Forum, 2012, vol. 706-709, pp. 135-142.

M. Niinomi, M. Nakai, M. Hendrickson, P. Nandwana, T. Alam, D. Choudhuri, and R. Banerjee: Scr. Mater., 2016, vol. 123, pp. $144-148$. 